\title{
Grazing winter wheat relieves plant water stress and transiently enhances photosynthesis
}

Matthew T. Harrison ${ }^{\mathrm{A}, \mathrm{B}}$, Walter M. Kelman ${ }^{\mathrm{A}}$, Andrew D. Moore ${ }^{\mathrm{A}}$ and John R. Evans ${ }^{\mathrm{B}}$

${ }^{\mathrm{A}}$ CSIRO Plant Industry, GPO Box 1600, Canberra ACT 2601, Australia

${ }^{\mathrm{B}}$ The Australian National University, Research School of Biology, GPO Box 475,

Canberra ACT 2601, Australia

Correspondence: M.T. Harrison. Telephone: +6126246 4892; Fax: +6126246

5166; e-mail: Matthew.Harrison@csiro.au

Date submitted: $\quad 13$ April 2010

Number of tables: 1

Number of figures: 5

Running title: $\quad$ Grazing wheat relieves water stress and increases photosynthesis

Keywords: $\quad$ Defoliation, herbivory, leaf area index, Rubisco, specific leaf area, transpiration 


\section{Abstract}

In order to model the impact of grazing on wheat growth, we measured photosynthesis in the field. Grazing may affect photosynthesis as a consequence of changes to leaf water status, nitrogen content per unit leaf area $\left(N_{\mathrm{a}}\right)$ or photosynthetic enzyme activity. While light-saturated $\mathrm{CO}_{2}$ assimilation rates $\left(A_{\text {sat }}\right)$ of field-grown wheat were unchanged during grazing, $A_{\text {sat }}$ transiently increased by $33-68 \%$ compared to ungrazed leaves over a two-four week period after grazing ended. Grazing reduced leaf mass per unit area, increased stomatal conductance and increased intercellular $\mathrm{CO}_{2}$ concentrations $\left(C_{\mathrm{i}}\right)$ by $36-38 \%, 88-169 \%$ and $17-20 \%$, respectively. Grazing did not alter $N_{\mathrm{a}}$. Using a photosynthesis model, we demonstrated that the increase in $A_{\text {sat }}$ after grazing required an increase in Rubisco activity of up to $53 \%$, whereas the increase in $C_{\mathrm{i}}$ could only increase $A_{\text {sat }}$ by up to $13 \%$. Increased Rubisco activity was associated with a partial alleviation of leaf water stress. We observed a $68 \%$ increase in leaf water potential of grazed plants which could be attributed to reduced leaf area index and canopy evaporative demand, as well as increased rainfall infiltration into soil. The grazing of rain-fed grain cereals may be tailored to relieve plant water stress and enhance leaf photosynthesis. 


\section{Introduction}

Dual-purpose wheat crops are used in mixed farming systems for both livestock forage and grain production. These crops present significant tactical and economic opportunities for farmers since they provide forage during colder months when growth rates of other pastures are low, and thus spare the grazing of other fields until growth increases with warmer spring temperatures. Although there have been many reports of reductions in grain yields after crop grazing (Winter and Thompson 1987; Kelman and Dove 2009), experiments have shown that in some circumstances grain yields are not affected by grazing (Virgona et al. 2006) and there are even reports of grazing increasing crop yields (Bortolini et al. 2005). Whilst there have been many studies that have examined the agronomic responses of dual-purpose cereals to grazing, physiological studies of such crops are lacking. This lack of information makes it difficult to interpret how various abiotic and biotic factors acting at the field scale affect leaf-level processes and ultimately crop growth. More specifically, the effect of grazing on winter wheat leaf photosynthetic responses is unknown. If the transient responses of crops to grazing at the leaf level were quantified, grazing regimes could be tailored so that optimal photosynthetic and potentially growth and yield responses could be achieved.

Reports of the effect of defoliation on leaf photosynthesis in other species are mixed. Defoliation of white birch (Oleksyn et al. 1998) and red clover (Kelly et al. 2005) caused depressions or no significant changes in leaf photosynthesis. In contrast, studies of herbs (von Caemmerer and Farquhar 1984), perennial forbs (Meyer 1998), grey and black alder (Oleksyn et al. 1998) and eucalyptus trees (Turnbull et al. 2007) have reported increases in photosynthesis after defoliation.

Photosynthetic responses of grasses to defoliation are also inconsistent. Fahnestock and Detling (2000) and Zhao et al. (2009) measured $\mathrm{CO}_{2}$ assimilation rates that were similar to or less than those measured before defoliation. Others (Nowak and Caldwell 1984; Anderson et al. 2006) have shown that photosynthesis of grass leaves increases after defoliation or grazing. Clearly, the species, environment, magnitude and pattern of defoliation will largely influence the degree to which photosynthetic responses differ. This makes it difficult to draw general conclusions about the effect of defoliation on 
Harrison et al. (2010) Grazing wheat relieves water stress and enhances photosynthesis

photosynthesis. Further, the majority of previous experiments have used perennial species, in contrast to the annual phenology of wheat. These observations underscore the need to explicitly measure the post-grazing photosynthetic responses of dualpurpose wheat.

Three pathways by which $\mathrm{CO}_{2}$ assimilation rate per unit leaf area $(A)$ may increase after defoliation include (1) improved leaf water status, (2) increased leaf nitrogen content and (3) increased activity of photosynthetic enzymes. First, defoliation may improve plant water status by increasing the root-leaf area ratio (Fay et al. 1993) and decreasing the rate of soil water use. Improved water availability increases stomatal conductance, which in turn increases $\mathrm{CO}_{2}$ supply to the sites of carboxylation and thus stimulates photosynthesis (Flexas et al. 2009). For example, Doescher et al. (1997) attributed increases in $A$ and conductance of Festuca idahoensis to an improvement in leaf water status, which in itself was caused by greater soil moisture availability in grazed sites.

The second means by which $A$ may increase after defoliation is via an increase in leaf nitrogen. Previous reports have shown that the increased nitrogen concentration can be caused by changes in soluble leaf protein (Nowak and Caldwell 1984). Increased soluble protein content is probably associated with increased Ribulose 1,5-bisphosphate carboxylase/oxygenase (Rubisco) content (Evans 1989), which would increase $A$. Indeed, increased photosynthesis after defoliation has been attributed to changes in nitrogen concentration or soluble protein in both short-lived perennial forbs (Morrison and Reekie 1995) and perennial bunchgrasses (Nowak and Caldwell 1984).

The third possible mode for a defoliation-induced increase of $A$ is an increase in the biochemical activity or the activation state of photosynthetic enzymes (Wareing et al. 1968). Von Caemmerer and Farquhar (1984) showed that $A$ increased in Phaseolus vulgaris due to an increase in the activity of Rubisco. More recently, Turnbull et al. (2007) showed that the transient increase in photosynthesis following partial defoliation of Eucalyptus globulus leaves was largely a result of increased enzyme activity, rather than the quantity of photosynthetic enzymes (which would be associated with increased leaf nitrogen content).

Most previous studies have examined photosynthetic responses either under laboratory conditions (von Caemmerer and Farquhar 1984), artificial defoliation (Turnbull et al. 
2007) or in perennial species (Fahnestock and Detling 2000). The current study was conducted since there is a dearth of information on the photosynthetic responses of rainfed, field-grown winter wheat to livestock grazing. Soil water, leaf water potential, gas exchange and nitrogen content were measured during and after grazing to determine whether one or more of the mechanisms outlined above influenced post-grazing photosynthetic responses. Specifically, the aims of this study were (1) to determine whether grazing affects leaf photosynthesis in field-grown wheat; and if so (2) to determine whether photosynthetic differences are due to leaf water status, the amount of leaf nitrogen or photosynthetic enzyme activity. This work represents the first step towards tailoring grazing management to optimise photosynthetic responses under field conditions. 


\section{Materials and Methods}

\section{Site description and crop management}

All experiments were conducted in the field at the CSIRO Ginninderra Experiment Station near Canberra $\left(35^{\circ} 12^{\prime} \mathrm{S} 149^{\circ} 03^{\prime} \mathrm{E}, 610 \mathrm{~m}\right.$ above sea level, mean rainfall 610 mm), ACT, Australia. On 21 March 2007, 1.2 $\mathrm{L} \mathrm{ha}^{-1}$ Roundup $^{\circledR}$ (active constituent glyphosate) and $1.60 \mathrm{~L} \mathrm{ha}^{-1} \mathrm{Duet}^{\circledR}$ (active constituents oryzalin and trifluralin) were applied to plots and winter wheat (Triticum aestivum L.) cv. Mackellar was then sown at $100 \mathrm{~kg} \mathrm{ha}^{-1}$ in $0.18 \mathrm{~m}$ row spacings with a commercial combine. Seed was sown with $110 \mathrm{~kg} \mathrm{ha}^{-1}$ of diammonium phosphate (DAP) fertiliser (N:P:K = 15:13:10.3). Average seedling density was 170 plants $\mathrm{m}^{-2}$ at emergence on 1 April 2007. The herbicide Dual ${ }^{\circledR}$ (active constituent metalachlor) was applied at $0.30 \mathrm{~L} \mathrm{ha}^{-1}$ on 24 March 2007. On 8 May 2007, the herbicides Topik $^{\circledR}$ (active constituents cloquintocet-mexyl, clodinafoppropargyl) and Lontrel ${ }^{\circledR}$ (active constituent clopyralid) were applied at 0.21 and $0.30 \mathrm{~L}$ $\mathrm{ha}^{-1}$ respectively, for control of ryegrass (Lolium perenne) and capeweed (Arctotheca calendula). To prevent nitrogen deficiencies, the crop was top-dressed with 51 and 37 $\mathrm{kg} \mathrm{N} \mathrm{ha}{ }^{-1}$ as urea on 21 May and 10 September 2007, respectively.

As far as possible, crop management in 2008 was conducted in a manner consistent with that in 2007. Differences in 2008 were (1) crops were sown on 1 April 2008 with 105 $\mathrm{kg} \mathrm{ha}^{-1}$ of DAP fertiliser and treated with $1.20 \mathrm{~L} \mathrm{ha}^{-1}$ Roundup $^{\circledR}, 1.60 \mathrm{~L} \mathrm{ha}^{-1}$ Duet $^{\circledR}$ and $30 \mathrm{~g} \mathrm{ha}^{-1}$ Logran $^{\circledR}$ (active constituent triasulfuron) pre-emergence, (2) average emergence density on 10 April 2008 was 217 plants $\mathrm{m}^{-2}$, (3) $55 \mathrm{~kg} \mathrm{~N} \mathrm{ha}^{-1}$ as urea was applied on 6 August 2008, and (4) $0.70 \mathrm{~L} \mathrm{ha}^{-1}$ of low-volatile ester MCPA $500^{\circledR}$ (active constituent 2-ethyl hexyl ester) and $0.075 \mathrm{~L} \mathrm{ha}^{-1}$ Lontrel $^{\circledR}$ were applied on 28 August 2008 for control of dicotyledonous weeds.

\section{Experimental design and animal management}

Treatments were based on farming systems representative of those conducted in south eastern Australia and were designed to test the effect of grazing intensity and duration on wheat photosynthetic responses, soil water use, biomass accumulation and grain yield. Importantly, this meant that additional resources such as irrigation were not 
applied since the results of such treatments would be atypical of mixed-farming systems in this region. In 2007, there were three grazing treatments in addition to an ungrazed control, a 'light' grazing intensity for a relatively 'long' period (LL), a 'heavy' grazing intensity for a 'short' period (HS) and a light grazing for a short period (not reported on here)..All grazing treatments began on 18 June in 2007. In 2008, only the ungrazed and HS treatments were conducted (1-31 July). Merino hoggets aged 12-24 months were allowed to graze plots for one or two months in the short and long treatments, respectively (Table 1). Cereal growth stages (Zadoks et al. 1974) were monitored weekly by dissecting the main stems of two plants per plot then inspecting them under the microscope. In all treatments, sheep were removed before cereal growth stage 30, preventing decapitation of apical meristems as they began to elongate. Experiments were conducted as randomised complete block designs with three replicates of each treatment, including ungrazed controls.

\section{Gas exchange measurements}

Seasonal leaf photosynthesis

Light-saturated $\mathrm{CO}_{2}$ assimilation rate per unit leaf area $\left(A_{\text {sat }}\right)$ was measured in 2007 and 2008, but over a greater duration and at a higher frequency in the second year. Saturating irradiance was estimated from irradiance response curves to be 2000 and $1800 \mu \mathrm{mol}$ photosynthetically active radiation (PAR) photons $\mathrm{m}^{-2} \mathrm{~s}^{-1}$ in 2007 and 2008 respectively. Measurements were made on ten similarly aged leaves per plot (30 per

Table 1. Grazing periods, termination dates, densities and intensities of treatments applied in 2007 and 2008. $\mathrm{C}=$ control, $\mathrm{HS}=$ heavy short and LL = light long.

\begin{tabular}{lllll}
\hline $\begin{array}{l}\text { Grazing } \\
\text { treatment }\end{array}$ & $\begin{array}{l}\text { Total grazing } \\
\text { days }\end{array}$ & End grazing & $\begin{array}{l}\text { Grazing } \\
\text { density } \\
\text { (DSE }^{\mathbf{A}} \mathbf{~ h a}^{-\mathbf{1}} \text { ) }\end{array}$ & $\begin{array}{l}\text { Grazing intensity } \\
\text { (DSE days ha }^{-\mathbf{1}} \text { ) }\end{array}$ \\
\hline $\mathrm{C}$ & 0 & - & 0 & 0 \\
$\mathrm{HS}$ & 31 & 19 July 2007 & 67.3 & 2086 \\
$\mathrm{HS}$ & 30 & 31 July 2008 & 65.5 & 1965 \\
LL & 62 & 19 August 2007 & 33.7 & 2086 \\
\hline
\end{tabular}

${ }^{\mathrm{A}} \mathrm{DSE}=$ dry sheep equivalents 
treatment) on 14 August, 28 August, 10 September and 16 October in 2007 and on eight leaves per plot (24 per treatment) on 30 July, 4 August, 11 August, 20 August, 2 September, 10 September, 29 September and 29 October in 2008 using an infra-red gas analyser (IRGA) (LI-6400, LI-COR Inc., Lincoln, NE, USA) open gas exchange system. All measurements were made on randomly sampled fully emerged non-necrotic leaves, as the aim was to assess the difference in the mean representative leaf photosynthetic state between treatments across time. Different plants were selected for each measurement. Cereal growth stages between the end of grazing and anthesis were not recorded but the number and age of leaves on grazed and ungrazed plants at each measurement time were similar. In both years, seasonal measurements were taken with two IRGAs concurrently to reduce the diurnal measurement period and allow crosschecking of the calibration consistency. Steady-state $A_{\text {sat }}$ measurements were made on leaves at an ambient $\mathrm{CO}_{2}$ concentration $\left(C_{\mathrm{a}}\right)$ of $380 \mu \mathrm{mol} \mathrm{mol}{ }^{-1}$, between 10:00 and 14:00 $\mathrm{h}$ on clear sunny days. Flow rates were set to $500 \mu \mathrm{mol} \mathrm{s}{ }^{-1}$ and the relative humidity of air entering the leaf chamber was allowed to follow ambient levels. All leaves in each block of plots were measured at constant leaf temperature $\left(T_{\text {leaf }}\right)$; these were set at $2^{\circ} \mathrm{C}$ above ambient at the beginning of each block. Mean $T_{\text {leaf }}$ ( \pm one standard error of the mean) over the season varied from $14.4 \pm 0.3^{\circ} \mathrm{C}$ to $28.5 \pm 0.2^{\circ} \mathrm{C}$ in 2007 and $14.9 \pm 0.2^{\circ} \mathrm{C}$ to $23.6 \pm 0.1{ }^{\circ} \mathrm{C}$ in 2008 . Each IRGA was calibrated daily, and sample and reference IRGAs were matched prior to each leaf measurement.

\section{Diurnal leaf photosynthesis}

A diurnal time course of net $\mathrm{CO}_{2}$ assimilation per unit leaf area at ambient light $(A)$ was measured on three independent representative leaves per treatment at 06:00, 08:00, 09:30, 10:30, 11:20, 12:30, 13:30 and 14:30 h on 27 August 2008. The IRGA was fitted with a clear chamber head so that leaves were exposed to ambient irradiance and the temperature control turned off so that diurnal variation in $T_{\text {leaf }}$ was representative. The relative humidity of air entering the chamber was also allowed to follow ambient conditions. 


\section{Sensitivity analysis of biochemical parameters}

A sensitivity analysis was performed to determine the relative influence of stomatal conductance $\left(g_{\mathrm{w}}\right)$ (via intercellular $\mathrm{CO}_{2}$ concentration, $C_{\mathrm{i}}$ ) and the maximum in vivo rate of carboxylation ( $V_{\mathrm{cmax}}$ ) on $A_{\text {sat }}$ in grazed plots. $A_{\text {sat }}$ is limited either by $V_{\text {cmax }}$ or the rate of electron transport $(J)$ which determines the rate of ribulose 1,5-bisphosphate (RuBP) regeneration. The $C_{\mathrm{i}}$ at the transition from a $V_{\text {cmax }}$ to a $J$ limitation of $A_{\text {sat }}$ depends on $T_{\text {leaf, }}$ irradiance and to a lesser extent the concentration of oxygen in the sub-stomatal cavities, $O$ (von Caemmerer and Farquhar 1981). The main variable affecting the $C_{\mathrm{i}}$ transition point was temperature. $O$ was assumed to be constant. Because $C_{\mathrm{i}}$ values for $A_{\text {sat }}$ were generally below the transition point, $V_{\text {cmax }}$ was calculated for each $A_{\text {sat }}$ measurement using equation 1 (von Caemmerer and Farquhar 1981):

$$
V_{\mathrm{c} \max }=\frac{\left(A_{\mathrm{sat}}+R_{\mathrm{d}}\right)\left(C_{\mathrm{i}}+K_{\mathrm{c}}\left(1+O / K_{\mathrm{o}}\right)\right)}{C_{\mathrm{i}}-\Gamma_{*}}
$$

with kinetic constants of Rubisco $\left(K_{\mathrm{c}}\right.$ and $K_{\mathrm{o}}$, the Michaelis-Menten constants for $\mathrm{CO}_{2}$ and $\mathrm{O}_{2}$, respectively, and $\Gamma^{*}$, the $\mathrm{CO}_{2}$ compensation point in the absence of dark respiration, $R_{\mathrm{d}}$ ) adopted from von Caemmerer et al. (1994) assuming infinite internal conductance. Temperature dependence functions were taken from von Caemmerer (2000) and were calculated at the measured $T_{\text {leaf. }} R_{\mathrm{d}}$ was assumed equal to 0.1 of $A_{\text {sat. }}$.

To determine the sensitivity of $A_{\text {sat }}$ to $V_{\text {cmax }}$ or $C_{\mathrm{i}}$, either the mean $V_{\text {cmax }}$ or $C_{\mathrm{i}}$ from the grazed treatment was substituted into equation 2 , whilst holding all other variables as for the ungrazed control:

$$
A_{\mathrm{sat}}=\frac{V_{\mathrm{cmax}}\left(C_{\mathrm{i}}-\Gamma_{*}\right)}{\left(C_{\mathrm{i}}+K_{\mathrm{c}}\left(1+O / K_{\mathrm{o}}\right)\right)}-R_{\mathrm{d}}
$$

The ratio of recalculated $A_{\text {sat }}\left(A_{\text {recalc }}\right.$ ) from equation 2 to the measured ungrazed $A_{\text {sat }}$ ( $A_{\text {ungrazed }}$ ) was compared with the ratio of the measured grazed to ungrazed $A_{\text {sat }}$ at each date. The recalculated ratio $\left(A_{\text {recalc }} / A_{\text {ungrazed }}\right)$ allowed inspection of the relative influence of $V_{\text {cmax }}$ or $C_{\mathrm{i}}$ on $A_{\text {sat }}$ in grazed treatments across time. 
Harrison et al. (2010) Grazing wheat relieves water stress and enhances photosynthesis

\section{Leaf mass per unit area (LMA), leaf nitrogen content $\left(N_{\mathrm{a}}\right)$ and leaf area index} (LAI)

Following each gas exchange measurement, the section of leaf in the IRGA chamber was outlined and the leaf detached at the ligule. Leaves were sealed in airtight plastic bags and stored on ice until daily measurements were completed. In the laboratory, marked leaf sections were excised and passed through a leaf area meter (L3100, LICOR Inc., Lincoln, NE, USA) before being dried at $80^{\circ} \mathrm{C}$ for $48 \mathrm{~h}$. The ratio of the leaf dry mass to its segment area was used to calculate the leaf mass per unit leaf area $(L M A)$. Each dried leaf segment was then separately ground in a ball mill. The nitrogen concentration of $1.2 \mathrm{mg}$ of dried material was assayed using an elemental analyser (EA 1110 CHNO; Carlo-Erba Instruments, Milan, Italy). Leaf nitrogen content $\left(N_{\mathrm{a}}\right)$ was calculated as the product of nitrogen concentration and $L M A$. Nitrate content of grazed and ungrazed leaves on 20 August and 2 September 2008 were measured using the method of Cataldo et al. (1975).

Shoot biomass from eight one-metre lengths of row were randomly sampled within each plot (equivalent to a $1.44 \mathrm{~m}^{2}$ quadrat) every two-three weeks in 2007 and 2008. Since the mixture of leaf sizes was relatively homogeneous in each sample, grab-samples were deemed an appropriate method of subsampling. Subsamples were separated into leaf lamina (excised at the ligule), stems (including leaf sheath) and senescent biomass (predominantly leaves). Bulk and subsampled fractions were dried at $70^{\circ} \mathrm{C}$ for $48 \mathrm{~h}$ then weighed. Leaf area per unit ground area (leaf area index, $L A I$ ) was calculated using equation 3:

$$
L A I=\frac{L D M_{\mathrm{SS}}}{T D M_{\mathrm{ss}}} \times \frac{T D M}{1.44} \times \frac{1}{L M A}
$$

where $L D M_{\mathrm{ss}}$ and $T D M_{\mathrm{ss}}$ represent the leaf and total shoot dry matter in the subsample respectively, and TDM is the total dry matter of shoot biomass from the quadrat. 


\section{Leaf water potential}

Leaf water potential $(\psi)$ of four representative leaves per plot was measured on 29 July, 12 August, 19 August, 21 August and 4 September 2008. The aim of $\psi$ measurements was to contrast values between treatments at the same time of the day when $A_{\text {sat }}$ was measured, so measurements were conducted between 10:00 and 13:00 h on clear, sunny days. Approximately $20 \mathrm{~mm}$ of leaf segment was detached, sealed in a custom-built brass thermocouple-psychrometer and equilibrated at $20^{\circ} \mathrm{C}$ for $4 \mathrm{~h}$. Dew point was measured using a microvolt meter (Westcor Inc., Model HR-33T, Logan, Utah, USA) and $\psi$ was calculated using calibration and measurement protocols described by Morgan (1980).

\section{Soil water}

Soil water content was measured using a neutron moisture meter (503 DR Hydroprobe, CPN Corporation, USA). Aluminium tubes with $50 \mathrm{~mm}$ outside diameter were installed in the centre of each plot (three tubes per treatment) to a depth of $1.8 \mathrm{~m}$. Calibration curves for moisture meter counts were constructed with gravimetrically measured soil samples when tubes were installed and immediately after harvest. Soil water content was measured at $150 \mathrm{~mm}$ increments to $1.4 \mathrm{~m}$ on approximately three-week intervals in 2007-8. As there were no significant differences in soil water content between treatments for layers deeper than $375 \mathrm{~mm}$, only changes in soil water content in this layer are reported here.

\section{Statistical analysis}

Temporal differences between means were analysed using repeated measures residual maximum likelihood (REML) models, with grazing treatment as a fixed factor. Correlations within treatments across time were fitted with order one ante-dependence models. $A_{\text {sat }}, g_{\mathrm{w}}$ and $L M A$ in 2007 were square-root transformed; in 2008 seasonal and diurnal $g_{\mathrm{w}}$ were square-root and natural-logarithm transformed respectively to meet the variance-homogeneity assumptions of statistical tests. Differences between means at each time were deemed significant if they were greater than the corresponding treatment 
Harrison et al. (2010) Grazing wheat relieves water stress and enhances photosynthesis

$\times$ time Fischer's least significant difference (LSD) for that time. Mixed-linear REML models were used to test treatment differences between (1) the change in mean $A_{\text {sat }}$ over the period between 1 and 20 August 2008, (2) mean LMA over the period between 1 and 20 August, (3) the change in soil water content between 18 June and 21 July 2008, (4) soil water extraction between 21 July and 7 October 2008 and (5) mean leaf nitrate content on 20 August and 2 September 2008. The 0.05 level of significance was adopted for all statistical tests unless otherwise stated. Statistical analyses were performed using GenStat Release 12.1 (Lawes Agricultural Trust, Rothamsted Experimental Station, UK). 


\section{Results}

Seasonal gas exchange, $L M A, N_{\mathrm{a}}$ and $L A I$ trends during 2007

On 14 August, approximately four weeks after the end of the HS grazing treatment, the $A_{\text {sat }}$ of representative regrowing leaves on grazed plants ('grazed leaves') was greater than that of controls (Fig. 1a). The LL plants were still being grazed at this time and their $A_{\text {sat }}$ was not significantly different to controls. Following the end of LL grazing on 18 August, the $A_{\text {sat }}$ of this treatment transiently increased for two to four weeks (Fig. $1 a)$. The $A_{\text {sat }}$ of all treatments dropped substantially between 14 September and 16 October due to senescence of ageing leaves, diminishing water supply (total water under the control decreased from $76 \pm 6 \mathrm{~mm}$ to $52 \pm 6 \mathrm{~mm}$ ) and increasing temperatures (average leaf temperature $\left(T_{\text {leaf }}\right)$ increased from $17.7 \pm 0.6^{\circ} \mathrm{C}$ to $26.2 \pm 0.3^{\circ} \mathrm{C}$ ). There was a tendency $(P=0.11)$ for a conservation of soil water in the uppermost $375 \mathrm{~mm}$ after each grazing treatment ended (data not shown). Stomatal conductances to water vapour $\left(g_{\mathrm{w}}\right)$ of both grazing treatments were greater than the ungrazed treatment on 14 August, but the difference between grazing treatments was not significant (Fig. 1b). This suggests that the $A_{\text {sat }}$ difference between the HS and LL treatments on this date was not due to $g_{\mathrm{w}}$. Trends in intercellular $\mathrm{CO}_{2}$ concentration $\left(C_{\mathrm{i}}\right)$ were similar to those in $g_{\mathrm{w}}$ (Fig. 1c), with the $C_{\mathrm{i}}$ of both grazing treatments being greater than that of the control on 14 August. Leaf dry mass per unit leaf area ( $L M A)$ was significantly reduced during both grazing treatments, and the LMA of LL plants continued to decrease after the end of this treatment (Fig. 1d). There were no consistent shifts in leaf nitrogen content per unit leaf area $\left(N_{\mathrm{a}}\right)$ after grazing was terminated, nor were there consistent $N_{\mathrm{a}}$ differences between treatments over the season (Fig. 1e). At the end of the HS and LL treatments on 19 July and 19 August, leaf area per unit ground area (leaf area index, $L A I$ ) was 89\% and $66 \%$ less than the ungrazed treatment, respectively (HS not shown, LL Fig. 1f). Maximum LAI occurred around 17 September in the HS and control treatments but peaked around two weeks later in the LL treatment. The $L A I$ of the HS treatment was similar to control values by mid-September, whereas the $L A I$ of the LL treatment was less than the control until much later in the season. 

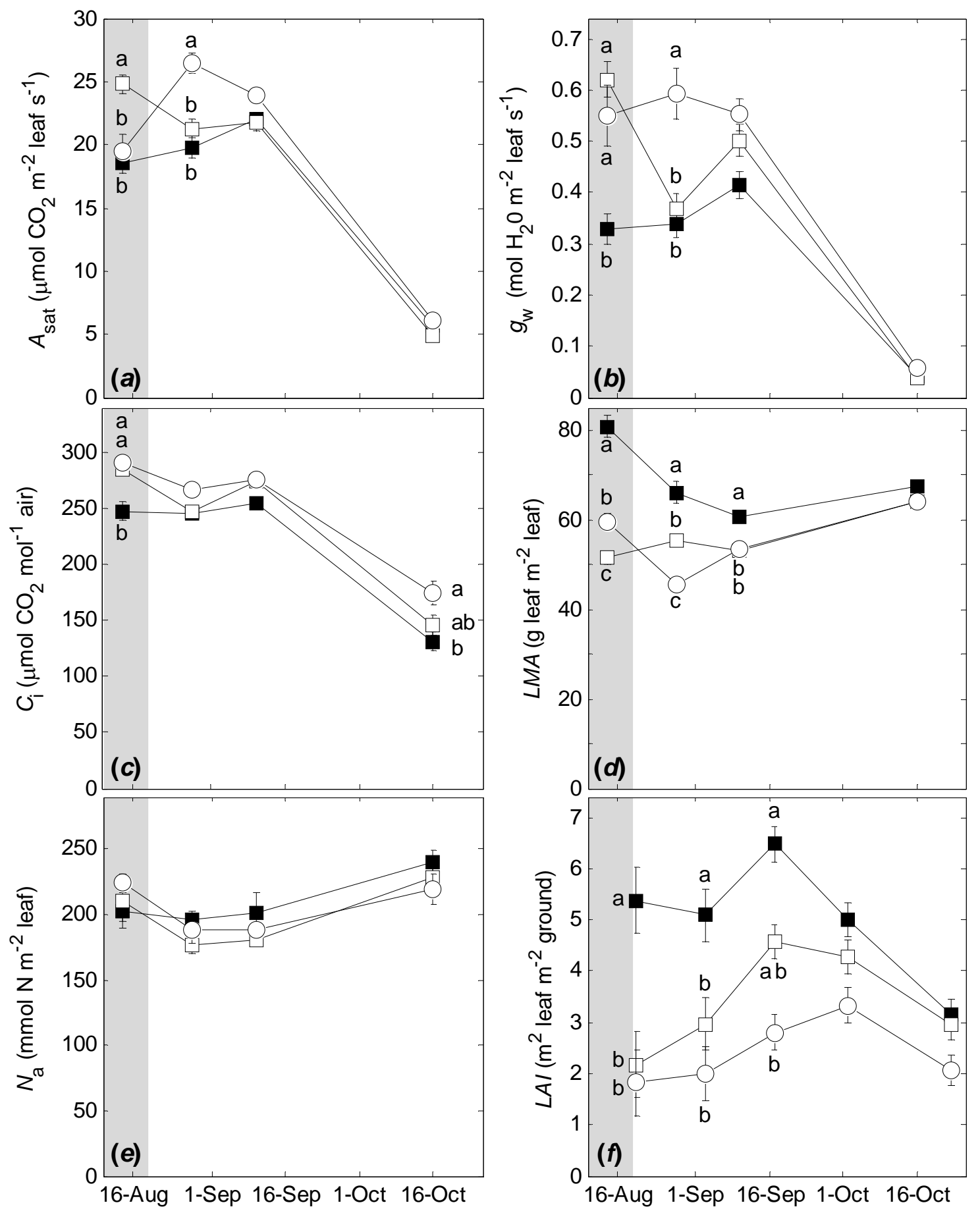

Fig. 1. Seasonal trends in (a) light-saturated net $\mathrm{CO}_{2}$ assimilation $\left(A_{\mathrm{sat}}\right),(\boldsymbol{b})$ stomatal conductance to water vapour $\left(g_{\mathrm{w}}\right),(\boldsymbol{c})$ intercellular $\mathrm{CO}_{2}$ concentration $\left(C_{\mathrm{i}}\right)$, (d) leaf mass per unit area of leaf $(L M A),(\boldsymbol{e})$ leaf nitrogen content per unit leaf area $\left(N_{\mathrm{a}}\right)$ and $(\boldsymbol{f})$ average leaf area index ( $L A I)$ of heavy short (open squares) and light long (open circles) grazing treatments during 2007. Ungrazed treatments are shown as closed squares. The shaded region shows the final part of the LL grazing treatment. Points represent means \pm one standard error of the mean (SEM) for $n=30$. Different letters indicate significant differences between means within each measurement period $(P \leq 0.05)$. 


\section{Seasonal gas exchange, $L M A, N_{\mathrm{a}}$ and $L A I$ trends during 2008}

In most cases, $A_{\text {sat }}$ trends of the grazed treatment in 2008 confirmed results observed in 2007, with a transient increase in $A_{\text {sat }}$ after sheep were removed on 1 August that continued until around 20 August (Fig. $2 a$, LSD $=3.3 \mu \mathrm{mol} \mathrm{m} \mathrm{s}^{-1}$ ). The difference in $A_{\text {sat }}$ between grazed and control leaves declined to a minimum on 10 September, but $A_{\text {sat }}$ of grazed leaves was again greater than controls by 31 October. Twelve days (11 August) after the end of grazing, $g_{\mathrm{w}}$ and $C_{\mathrm{i}}$ of grazed leaves had increased by $85 \%$ and $6 \%$ respectively (Figs. $2 b$ and $c$ ). Mean $L M A$ was reduced during grazing and continued to decline after grazing until 11 August (Fig. $2 d$ ). In the fortnight after grazing, the time-averaged LMA of grazed leaves was lower than that of controls (59 cf. $88 \mathrm{~g} \mathrm{~m}^{-2}$, $\mathrm{LSD}=5 \mathrm{~g} \mathrm{~m}^{-2}$ ), but differences were not significant from 1 September onwards. $T_{\text {leaf }}$ varied from $11.7^{\circ} \mathrm{C}$ on 11 August to $23.6^{\circ} \mathrm{C}$ on 29 September, but was not significantly different between treatments on any day. $N_{\mathrm{a}}$ was not affected by grazing except for the first and last measurements (Fig. 2e). On 20 August and 2 September 2008, leaf nitrate represented less than $10 \%$ of total leaf nitrogen and did not differ between grazed and control leaves. By the end of grazing $L A I$ was reduced by $82 \%$ from $2.8 \pm 0.3$ to $0.5 \pm$ $0.3 \mathrm{~m}^{2}$ leaf $\mathrm{m}^{-2}$ ground, compared to an increase in the control from $2.9 \pm 0.2$ to $3.9 \pm$ $0.2 \mathrm{~m}^{2} \mathrm{~m}^{-2}$ (initial values not shown, final values shown in Fig. $2 f$ ). During the first six weeks after sheep were removed, $L A I$ of grazed plots increased rapidly, but did not reach ungrazed $L A I$ values before senescence began in early October.

\section{Seasonal trends in leaf water potential and soil water during 2008}

Leaf water potential $(\psi)$ was not altered during grazing but increased for three weeks after the end of grazing until around 19 August (Fig. 3a). This coincided with the period of increasing $A_{\text {sat }}$ in grazed leaves (cf. Figs. $2 a$ and $3 a$ ). Before grazing the soil water content of grazed and ungrazed plots was similar (Fig. 3b), so later differences in soil water were attributed to grazing. A greater quantity of the $28 \mathrm{~mm}$ rainfall between the measurement dates on 18 June and 21 July was stored in soils of grazed plots compared with controls (27 and $17 \mathrm{~mm}$ respectively, LSD $=7 \mathrm{~mm}$ ). It is possible that canopy rainfall interception of the controls was greater as its $L A I$ was more than four times that of the grazed plots in early August (Fig. 2f). Moreover, rainfall events between 18 June and 21 July were small and numerous (rainfall was recorded on ten days and all but one were less than $5 \mathrm{~mm}$ ), which enhanced the possibility that intercepted rain evaporated 

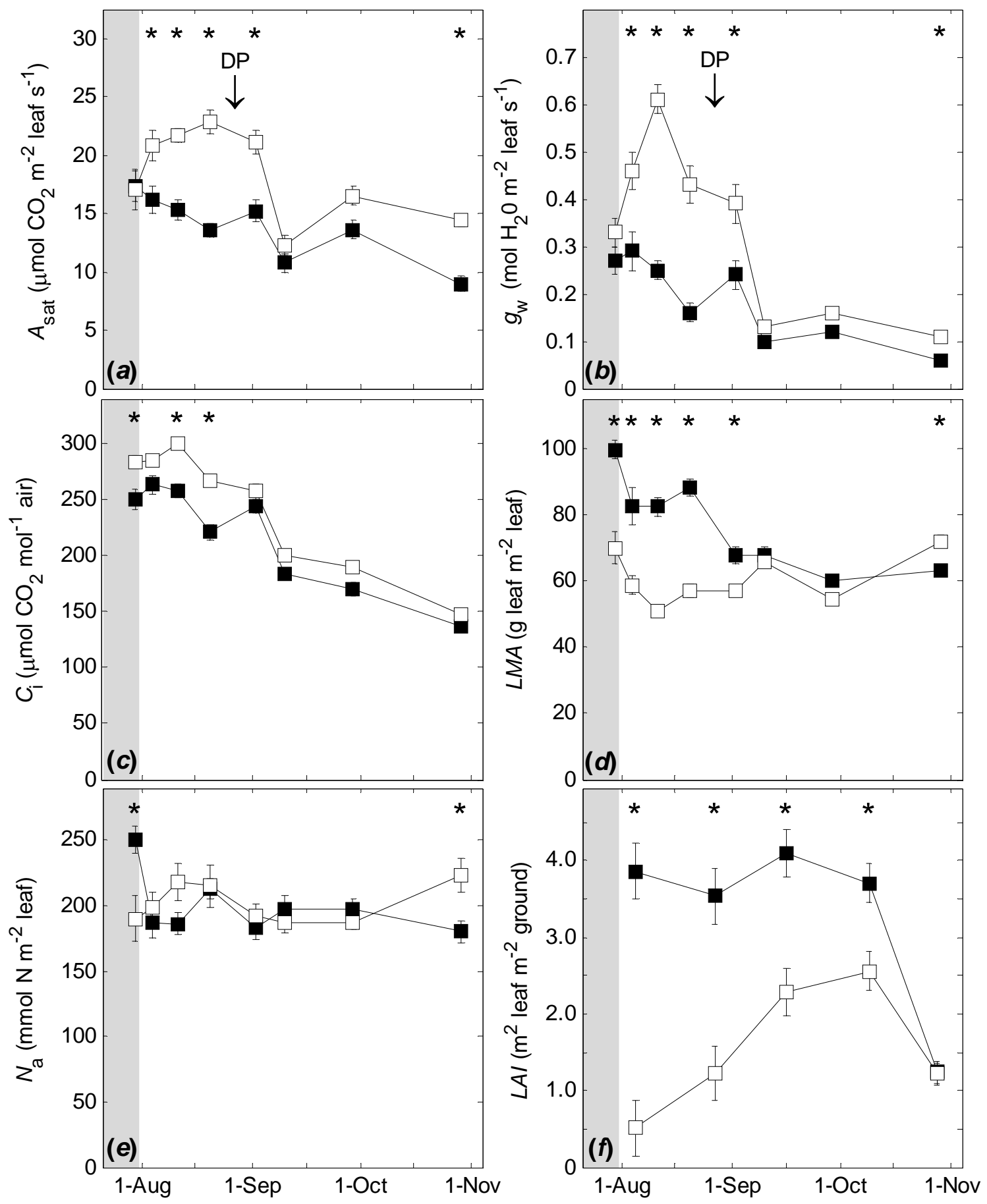

Fig. 2. Seasonal trends in (a) light-saturated net $\mathrm{CO}_{2}$ assimilation $\left(A_{\mathrm{sat}}\right)$, (b) stomatal conductance to water vapour $\left(g_{\mathrm{w}}\right)$, (c) intercellular $\mathrm{CO}_{2}$ concentration $\left(C_{\mathrm{i}}\right)$, (d) leaf mass per unit leaf area $(L M A),(\boldsymbol{e})$ leaf nitrogen content per unit leaf area $\left(N_{\mathrm{a}}\right)$ and $(f)$ average leaf area index ( $L A I)$ of grazed (open points) and ungrazed leaves (closed points) during 2008. The shaded region represents the final part of the grazing period and DP marks the date of diurnal photosynthesis measurement. Points represent means \pm one SEM for $n=24$. Asterisks $(*)$ indicate significant differences between means at each date $(P \leq$ $0.05)$. 

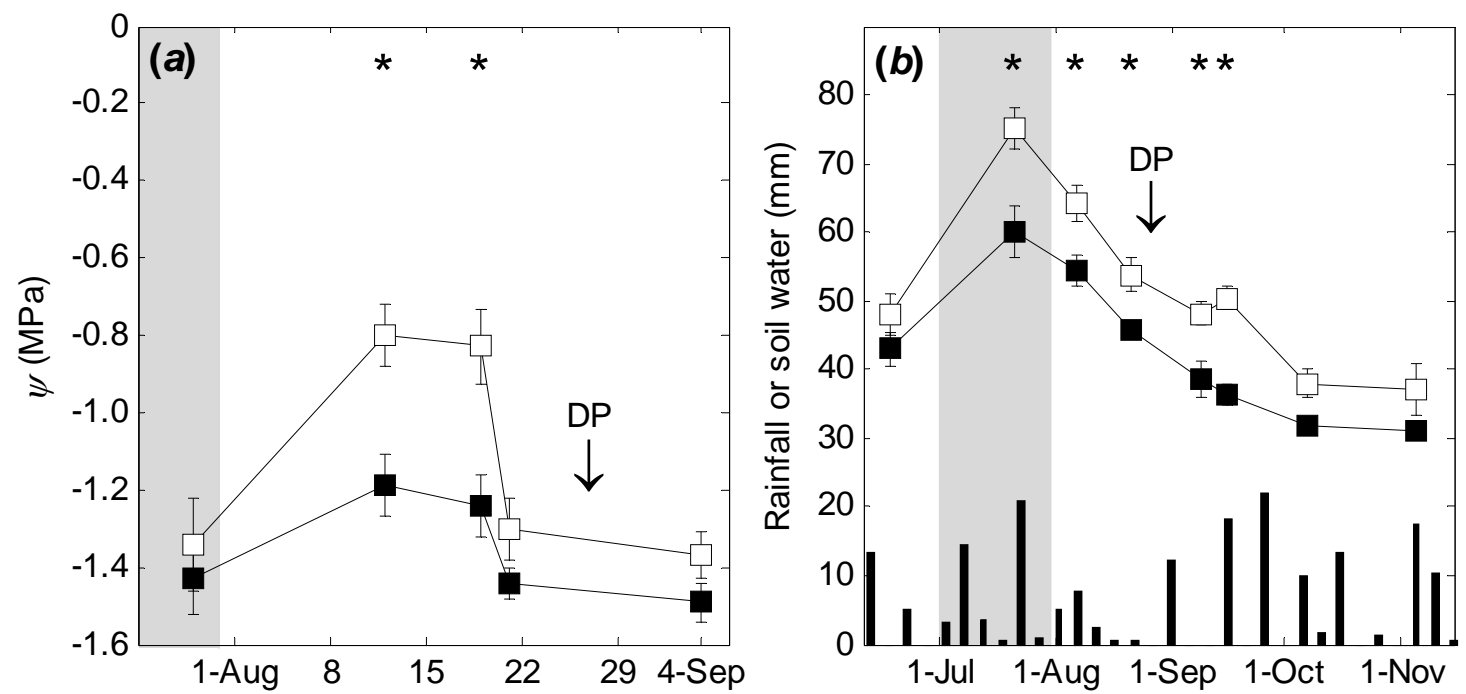

Fig. 3. (a) Leaf water potential $(\psi)$, (b) cumulative five-day rainfall (bars) and soil water content (squares) in the top $375 \mathrm{~mm}$ of soil of the grazed (open points) and ungrazed (closed points) plots during 2008. The shaded region denotes the grazing period and DP marks the date of diurnal photosynthesis measurement. Points represent means \pm one $\operatorname{SEM}(n=12$ and three in A and B respectively). Asterisks $(*)$ indicate significant differences between means at each date $(P \leq 0.05)$.

from the leaves of ungrazed crops. The conservation of soil water in grazed plots persisted throughout much of the remainder of the growing season (Fig. 3b). Grazed plots extracted $37 \mathrm{~mm}$ of water from the upper soil layer between 21 July and 7 October, compared to only $28 \mathrm{~mm}$ from the ungrazed plots (marginally significant, $P=$ $0.07, \mathrm{LSD}=11 \mathrm{~mm})$.

\section{Diurnal trends in leaf photosynthesis during 2008}

Since seasonal $A_{\text {sat }}$ was always measured on clear, sunny days between 10:00 and 13:00 $\mathrm{h}$ at saturating light (Figs. 1, 2), additional measurements were made on 27 August using a clear chamber on the LI-COR head to assess diurnal trends in photosynthesis $(A)$ at ambient light. There was no difference between treatments at $6: 30 \mathrm{~h}$, but photosynthesis of grazed leaves was greater than controls at 9:30, 12:30 and 13:30 $\mathrm{h}$ (Fig. 4a). The maximum difference between grazed and ungrazed $A$ occurred around noon, similar to differences in $g_{\mathrm{w}}$ (Fig. $4 b$ ). In contrast to the greater $C_{\mathrm{i}}$ observed in grazed leaves when measured over the season, there were no consistent differences in $C_{\mathrm{i}}$ between treatments when measured diurnally (cf. Figs. $2 c$ and $4 c$ ). Transpiration rates $(T)$ of leaves in the grazed treatment were greater than those in the ungrazed treatment at 12:30 and 13:30 h (Fig. 4d), consistent with $T$ measured over the growing season during 2008 (not shown). Increased plant available water on grazed plots (see arrow 

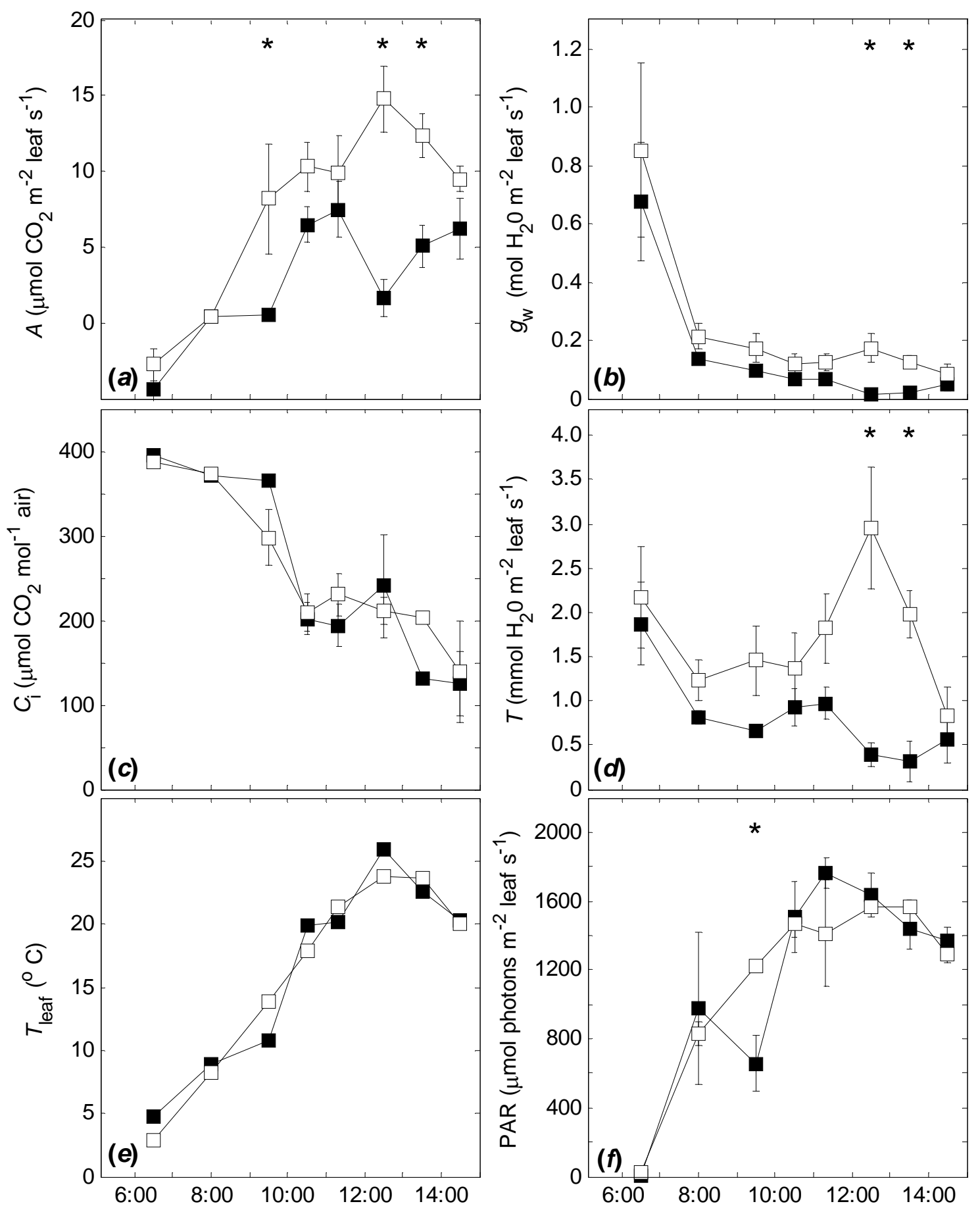

Fig. 4. Diurnal trends in (a) net $\mathrm{CO}_{2}$ assimilation $(A),(\boldsymbol{b})$ stomatal conductance to water vapour $\left(g_{\mathrm{w}}\right),(\boldsymbol{c})$ intercellular $\mathrm{CO}_{2}$ concentration $\left(C_{\mathrm{i}}\right),(\boldsymbol{d})$ leaf transpiration $(T),(\boldsymbol{e})$ leaf temperature $\left(T_{\text {leaf }}\right)$ and $(f)$ photosynthetically-active radiation (PAR) measured on representative, independent grazed (open points) and ungrazed (closed points) leaves on 27 August 2008, $27 \mathrm{~d}$ after the end of grazing. Points represent means \pm one SEM for $n$ $=$ three. Asterisks $(*)$ indicate significant differences between means at each date $(P \leq$ $0.05)$.

marked DP in Fig. $3 b$ ) resulted in higher leaf $\psi$ which enabled greater $g_{\mathrm{w}}, T$ and $A$. Peak diurnal $A$ coincided with maximum daily $T_{\text {leaf }}$ and photosynthetically active radiation, PAR (Figs. $4 e, f$ ). $T_{\text {leaf }}$ in the grazed treatment ranged from 2 to $25^{\circ} \mathrm{C}$, and incident PAR 
reached a maximum of $1800 \mu \mathrm{mol}$ photons $\mathrm{m}^{-2} \mathrm{~s}^{-1}$. The gradual closure of stomates during the day (Fig. 4b) was associated with the diurnal increase of air temperature and $T_{\text {leaf. }}$

\section{Physiological mechanisms underlying increased photosynthesis in grazed leaves and their relative importance}

Both seasonal and diurnal measurements revealed that increased photosynthesis of grazed leaves was not always associated with increases in $C_{\mathrm{i}}$ (Figs. $1 c, 4 c$ ) or to $N_{\mathrm{a}}$ (Figs. 1e, 2e). The impact of greater $V_{\mathrm{cmax}}$ or $C_{\mathrm{i}}$ on $A_{\text {sat }}$ was assessed assuming that the rate of $\mathrm{CO}_{2}$ assimilation was Rubisco limited (see methods). The ratio of the recalculated ungrazed $A_{\text {sat }}$ (after substituting either the mean $V_{\text {cmax }}$ or $C_{\mathrm{i}}$ from the grazed treatment, denoted $A_{\text {recalc }}$ ) to the original ungrazed $A_{\text {sat }}$ value (denoted $A_{\text {ungrazed }}$ ) was compared to the ratio of the measured $A_{\text {sat }}$ from the grazed treatment (denoted $A_{\text {grazed }}$ ) to $A_{\text {ungrazed }}$ (Fig. 5). In most cases, increased $A_{\text {sat }}$ after grazing was associated with increased $V_{\text {cmax }}$ rather than increased $C_{\mathrm{i}}$. The two occasions when the sensitivity of $A_{\text {sat }}$ to $C_{\mathrm{i}}$ was greater than that of $V_{\text {cmax }}\left(10,29\right.$ September) occurred when $A_{\text {sat }}$ on grazed plots was not significantly greater than that of controls (cf. Figs. $2 a$ and 5). Results in 2007 were comparable. The increased $A_{\text {sat }}$ of the HS treatment on 14 August (Fig. 1a)

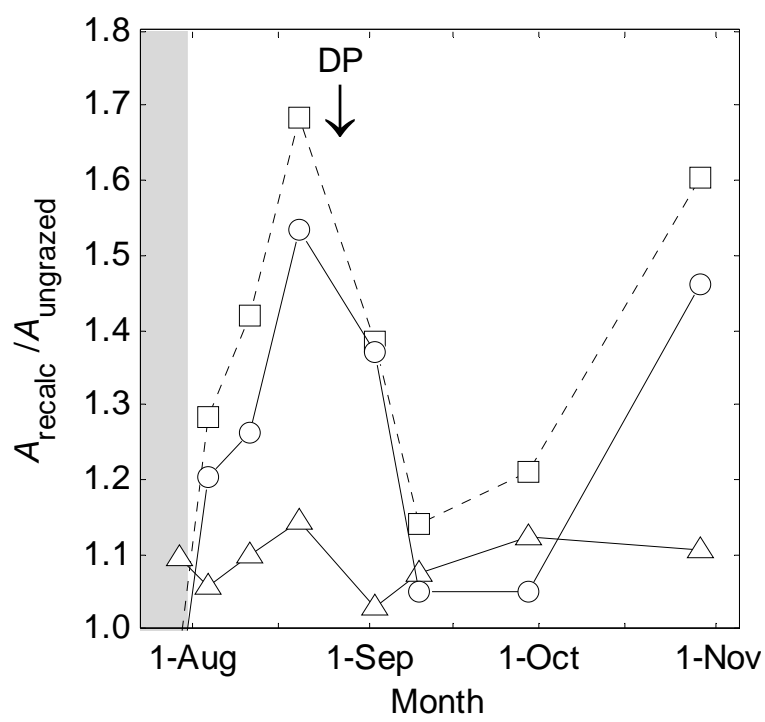

Fig. 5. Sensitivity analysis of the effect of $V_{\text {cmax }}$ or $C_{\mathrm{i}}$ on the increase in $A_{\text {sat }}$ observed in grazed plots relative to ungrazed control plots ( $\left.A_{\text {recalc }} / A_{\text {ungrazed }}\right)$ during 2008 . $A_{\text {recalc }}$ values were calculated by replacing either the mean $V_{\text {cmax }}$ (circles) or $C_{\mathrm{i}}$ (triangles) from the grazed treatment with that of the control and compared with the ratio of measured grazed to ungrazed $A_{\text {sat }}$ (squares). The arrow denotes the date of diurnal photosynthesis (DP) measurement. 
Harrison et al. (2010) Grazing wheat relieves water stress and enhances photosynthesis

was primarily attributable to $V_{\text {cmax }}$ rather than $C_{\mathrm{i}}\left(A_{\text {recald }} / A_{\text {ungrazed }}\right.$ values were 1.24 and 1.12 respectively). Similarly on 28 August 2007, the increase in $A_{\text {sat }}$ of the LL treatment was primarily a consequence of increased $V_{\text {cmax }}$, rather than increased $C_{\mathrm{i}}\left(A_{\text {recald }} / A_{\text {ungrazed }}\right.$ values were 1.29 and 1.08 , respectively).

In summary, results from both seasons suggested that the increased $A_{\text {sat }}$ after grazing was associated with increased Rubisco activity. The contribution of increased $g_{\mathrm{w}}$ and thus $C_{\mathrm{i}}$ to increased $A_{\text {sat }}$ in grazed leaves was relatively minor. The calculated increase in $V_{\text {cmax }}$ was not associated with an increased $N_{\mathrm{a}}$. 


\section{Discussion}

\section{$A_{\text {sat }}$ transiently increases after grazing}

In 2007, the maximum ratio of $A_{\text {sat }}$ of representative regrowing leaves on grazed plants ('grazed leaves') to that on ungrazed plants was 1.33; in 2008 this value was 1.68 . Assuming that the maximum increase in grazed leaf $A_{\text {sat }}$ was reasonably well captured by the measurement frequency, the most obvious candidates for differential responses between seasons in this study are $L A I$ and soil water content. It has been shown that greater removal of biomass tends to induce greater $A_{\text {sat }}$ responses (Pinkard et al. 2007), so the mean $L A I$ value of $1.8 \mathrm{~m}^{2} \mathrm{~m}^{-2}$ remaining after the LL grazing treatment in 2007 compared to $0.5 \mathrm{~m}^{2} \mathrm{~m}^{-2}$ at the end of grazing in 2008 may be partially responsible for the differences between seasons. However, given that the LAI at the end of the 2007 HS treatment was not significantly different to that at the end of grazing in 2008, there must have been another factor involved. The difference in size of the transient increase in $A_{\text {sat }}$ is most likely associated with differences in soil water content between seasons.

\section{Grazing relieves plant water stress}

Grazing crops may conserve soil water. This was demonstrated by the fact that the pregrazing soil water content in 2008 was similar between treatments but was significantly greater in grazed plots immediately after grazing. The increased $A_{\text {sat }}$ of grazed leaves relative to controls was likely associated with the increased soil water content. Greater $L A I$ of ungrazed canopies intercepts more rainfall and facilitates greater evaporative losses from leaf surfaces, thereby reducing soil water infiltration compared to grazed canopies. Grazed canopies may therefore have a reduced capacity to intercept rainfall, an increased supply of soil water and reduced transpiration relative to controls. Indeed, past studies using wheat (Virgona et al. 2006) have confirmed that grazing-induced reductions in leaf area may be manifest as a transient accumulation of soil water after grazing.

In all grazing regimes conducted in this study, $A_{\text {sat }}$ did not increase during grazing but increased for two-four weeks after the termination of grazing. In 2008, leaf water stress decreased in grazed plots between the end of grazing and mid-August, coinciding with 
the transient increase in $A_{\text {sat }}$. The reduced stress level in the grazed wheat had disappeared by late August as $\psi$ of grazed leaves substantially decreased and returned to levels observed in ungrazed leaves, followed by a decline in $A_{\text {sat }}$. The combination of increased soil water and reduced transpiration by the crop canopy would increase the supply-demand ratio of soil water and relieve water stress. However, as grazed crops regrew and approached full ground cover $(L A I \approx 3)$, the supply-demand ratio would fall leading to reduction of $A_{\text {sat }}$.

Differences in the magnitude of $A_{\text {sat }}$ responses to grazing between 2007 and 2008 may be attributed to a greater grazing-induced relief of water stress in 2008. Yang and Midmore (2004) observed large increases in the photosynthetic rate of water-stressed cotton after defoliation, compared to no significant changes in well-watered cotton. An increased supply of soil water has been shown to increase stomatal conductance (Shimada et al. 1992) and may thus reduce stomatal limitation of photosynthesis (Fay et al. 1993). Although the relationship between stomatal conductance and photosynthesis after defoliation has been measured in many studies, results are inconsistent. These are examined below.

\section{Grazing increases stomatal conductance $\left(g_{\mathrm{w}}\right)$}

Grazed wheat leaves had significantly greater $g_{\mathrm{w}}$ both during and after grazing. Such phenomena are often thought to be due to improved water status after grazing (Toft et al. 1987). Transient increases in $g_{\mathrm{w}}$ have been observed in previous defoliation studies (Doescher et al. 1997) and have been linked to increases in photosynthesis (Fay et al. 1993). Enhancement of $g_{\mathrm{w}}$ and photosynthesis after defoliation may be caused by increased root-leaf ratios, which improves the supply of water or nutrients to the leaves or may increase root to leaf hydraulic conductivity (Fay et al. 1993). On the other hand, both the present study (HS treatment on 14 August 2007) and previous reports (Turnbull et al. 2007) have shown that it is possible to observe increased photosynthesis after defoliation but no change in $g_{\mathrm{w}}$. Hence increased stomatal aperture after grazing cannot be the sole factor responsible for raising $A_{\text {sat }}$. Two other mechanisms underlying increased photosynthesis after grazing may include increasing (1) the abundance or (2) the activation state of Rubisco. These possibilities are observed as increased $N_{\mathrm{a}}$ or $V_{\text {cmax }}$ respectively, and are discussed in the following sections. 


\section{The effect of $N_{\mathrm{a}}$ and $L M A$ on $A_{\text {sat }}$ after grazing}

Both results of the present (Figs. 1e, 2e) and previous studies (Oleksyn et al. 1998; Pinkard et al. 1998) have demonstrated that defoliation may have no significant effects on the $N_{\mathrm{a}}$ of regrowth. However, contrary results have also been observed (Caldwell et al. 1981), and some reports have ascribed increased leaf nitrogen after defoliation as the reason for increased photosynthesis (Lavigne et al. 2001).

Much of the apparent contradiction between results may be explained by the dimensions of leaf nitrogen measurements. Experiments that report photosynthetic increases following defoliation typically express nitrogen per unit foliage dry mass (e.g., Hamilton and Frank 2001; Little et al. 2003) yet those that generally do not observe changes in leaf nitrogen after defoliation usually express this trait on an area basis (e.g. Pinkard et al. 1998). Both this study (Figs. 2d, 3d) and others (Little et al. 2003; Pinkard et al. 2007) have shown that $L M A$ of regrowth can decrease during or after defoliation. Consequently, increased leaf nitrogen concentration does not necessarily mean there should be concurrent changes in $N_{\mathrm{a}}$.

Since light capture is governed by leaf area and not leaf mass, it is more appropriate to express both photosynthesis and nitrogen on an area basis. This assertion was exemplified by Teixeira et al. (2008), who showed that $68 \%$ of the variation in photosynthesis of grazed lucerne could be explained by changes in $N_{\mathrm{a}}$, whereas there was no systematic effect of leaf nitrogen concentration on photosynthesis.

\section{Increased $A_{\text {sat }}$ was mainly associated with increased $V_{\text {cmax }}$ rather than increased $C_{\mathrm{i}}$}

Given that $N_{\mathrm{a}}$ did not change after grazing, the increase in $A_{\text {sat }}$ must have been due to increases in either (1) $g_{\mathrm{w}},(2)$ the activation state of Rubisco, (3) the proportion of leaf nitrogen allocated to Rubisco, or a combination of (1)-(3). To assess the relative importance of each mechanism on $A_{\text {sat }}$ in grazed leaves, a sensitivity analysis was conducted. The effects of $J$ or $R_{\mathrm{d}}$ on $A_{\text {sat }}$ were not considered because the majority of measurements had $C_{\mathrm{i}}$ values below the point at which $A_{\text {sat }}$ became limited by RuBP regeneration, and $R_{\mathrm{d}}$ was assumed to be a constant proportion of $A_{\text {sat }}$ (see methods). The analysis revealed that $V_{\text {cmax }}$ accounted for greater proportions of photosynthetic increases after grazing than $\operatorname{did} C_{\mathrm{i}}$ (Fig. 5). 
A similar conclusion was reached by Turnbull et al. (2007) with defoliated Eucalyptus globulus seedlings. They found that about $87 \%$ of the transient increase in leaf photosynthesis after defoliation was due to $V_{\text {cmax }}$, whereas only $13 \%$ of the increase was due to $g_{\mathrm{w}}$. Other studies (Wareing et al. 1968; von Caemmerer and Farquhar 1984) have also shown increased Rubisco activity after defoliation. Future Rubisco assays are required to confirm whether the increase in $V_{\text {cmax }}$ is due to increased activation state of existing Rubisco or to an increase in the partitioning of leaf nitrogen to Rubisco.

\section{Up-regulation of $A_{\text {sat }}$ after defoliation may be caused by reduced source-sink ratio}

Having gained some insight as to how $A_{\text {sat }}$ increases after defoliation, the question remains as to why the increase occurs. A common theory is that defoliation perturbs the source-sink balance, where organs that produce assimilate are known as sources and those that require assimilate are known as sinks. An accumulation of the primary endproducts of photosynthesis is thought to inhibit $\mathrm{CO}_{2}$ assimilation rate (Layne and Flore 1995). Previous evidence suggests that a reduction in the source-sink ratio by defoliation up-regulates photosynthesis on remaining leaf area through an increased sink demand for carbohydrate (Oleksyn et al. 1998). The up-regulation occurs as storage reserves decline after defoliation (Zhou and Quebedeaux 2003) and one mechanism by which this can be achieved is by increasing $V_{\text {cmax }}$ in remaining leaves (Lavigne et al. 2001). Conversely, experiments that have reduced priority sinks (e.g. stem girdling or fruit spikelet removal) have documented reductions in photosynthesis, implying that decreased demand for carbohydrate down-regulates photosynthesis and assimilate production (Zhou and Quebedeaux 2003).

\section{Changes in $A_{\text {sat }}$ were not due to altered canopy irradiance or leaf age structure}

Two other factors suggested as causes for increased photosynthesis after defoliation are increased irradiance (Anten and Ackerly 2001) or altered leaf age structure (Caldwell et al. 1981). The increase in $A_{\text {sat }}$ in this study was not due to increased irradiance, since all leaves had similar sunlight exposure before and during measurement (Fig. 4f). Increased $A_{\text {sat }}$ in grazed leaves was unlikely to be a result of changes in leaf age structure. Gas exchange measurements conducted on regrowing leaves within a row of clipped plants in the control plots found that $A_{\text {sat }}$ was not statistically different between clipped and adjacent plants in undefoliated rows (data not shown). These measurements were 
performed on 20 August 2008 when $A_{\text {sat }}$ differences between control and grazed plots were large. The control plants were clipped at the same time and to the same extent as those in adjacent plots were grazed, so it is reasonable to assume that phyllochrons and leaf ages on the two sets of defoliated plants were the same. Since the $A_{\text {sat }}$ of the clipped plants was not affected, these results imply that the transient increase in $A_{\text {sat }}$ in grazed plots was not due to leaf age, nor an increase in the root-leaf area ratio of individual plants but rather an alleviation of plant water stress.

\section{Conclusions}

The first aim of this experiment was to determine whether grazing affected $A_{\text {sat }}$ in rainfed, field-grown wheat. $A_{\text {sat }}$ was unchanged during grazing but transiently exceeded that of leaves in ungrazed treatments over two-four weeks after grazing was completed. The second aim was to determine whether the changes in $A_{\text {sat }}$ were due to (i) leaf water status, (ii) $N_{\mathrm{a}}$ or (iii) $V_{\text {cmax }}$. $A_{\text {sat }}$ in grazed plots increased relative to controls as $\psi$ and the soil water difference between treatments increased, so leaf water status was closely associated with increases in $A_{\text {sat }}$ after grazing. The transient increase in $A_{\text {sat }}$ after grazing was mainly explained by increases in $V_{\text {cmax }}$ rather than $C_{\mathrm{i}}$. Since $N_{\mathrm{a}}$ was not affected by grazing, the increased $V_{\text {cmax }}$ suggests an increased allocation of nitrogen to Rubisco and/or increased activation of Rubisco, but further work is required to distinguish between these possibilities. This study has demonstrated that under rain-fed conditions, livestock grazing of dual-purpose wheat can relieve plant water stress and enhance photosynthesis. Provided judicious management is maintained, future rotational grazing regimes of annual cereal crops may be conducted so that successive bouts of increased photosynthesis are realised over the course of the growing season. 


\section{Acknowledgements}

We appreciate the assistance of Stephanie $\mathrm{M}^{\mathrm{c}} \mathrm{Caffery}$ for nitrogen analyses, Phillip Dunbar for site management and Bruce Isaac for sheep management. We are grateful to Hugh Dove, Mark Smith and Scott $\mathrm{M}^{\mathrm{c}}$ Donald for help with field sampling. Thanks also to the GRDC and the Australian Government for financial support of this work. 


\section{References}

Anderson TM, Dong Y, McNaughton SJ. 2006. Nutrient acquisition and physiological responses of dominant Serengeti grasses to variation in soil texture and grazing. Journal of Ecology 94, 1164-1175.

Anten NPR, Ackerly DD. 2001. Canopy-level photosynthetic compensation after defoliation in a tropical understorey palm. Functional Ecology 15, 252-262.

Bortolini PC, de Moraes A, Carvalho PCD. 2005. Forage and grain yield of white oat under grazing. Brazilian Journal of Animal Science 34, 2192-2199.

Caldwell MM, Richards JH, Johnson DA, Nowak RS, Dzurec RS. 1981. Coping with herbivory - photosynthetic capacity and resource allocation in two semi-arid Agropyron bunchgrasses. Oecologia 50, 14-24.

Cataldo DA, Haroon M, Schrader LE, Youngs VL. 1975. Rapid colorimetric determination of nitrate in plant tissue by nitration of salicylic acid. Communications in Soil Science and Plant Analysis 6, 71-80.

Doescher PS, Svejcar TJ, Jaindl RG. 1997. Gas exchange of Idaho fescue in response to defoliation and grazing history. Journal of Range Management 50, 285-289.

Evans JR. 1989. Photosynthesis and nitrogen relationships in leaves of $\mathrm{C}_{3}$ plants. Oecologia 78, 9-19.

Fahnestock JT, Detling JK. 2000. Morphological and physiological responses of perennial grasses to long-term grazing in the Pryor Mountains, Montana. American Midland Naturalist 143, 312-320.

Fay PA, Hartnett DC, Knapp AK. 1993. Increased photosynthesis and water potentials in Silphium integrifolium galled by cynipid wasps. Oecologia 93, 114-120.

Flexas J, Baron M, Bota J, Ducruet JM, Galle A, Galmes J, Jimenez M, Pou A, RibasCarbo M, Sajnani C, Tomas M, Medrano H. 2009. Photosynthesis limitations during water stress acclimation and recovery in the drought-adapted Vitis hybrid Richter-110 (V. berlandieri $\mathrm{x} V$. rupestris). Journal of Experimental Botany 60, 2361-2377.

Hamilton EW, Frank DA. 2001. Can plants stimulate soil microbes and their own nutrient supply? Evidence from a grazing tolerant grass. Ecology 82, 2397-2402.

Kelly KB, Stockdale CR, Mason WK. 2005. The productivity of irrigated legumes in northern Victoria. 2. Effect of grazing management. Australian Journal of Experimental Agriculture 45, 1577-1585.

Kelman WM, Dove H. 2009. Growth and phenology of winter wheat and oats in a dualpurpose management system. Crop \& Pasture Science 60, 921-932.

Lavigne MB, Little CHA, Major JE. 2001. Increasing the sink:source balance enhances photosynthetic rate of 1-year-old balsam fir foliage by increasing allocation of mineral nutrients. Tree Physiology 21, 417-426. 
Layne DR, Flore JA. 1995. End product inhibition of photosynthesis in Prunus cerasus $\mathrm{L}$ in response to whole plant source-sink manipulation. Journal of the American Society for Horticultural Science 120, 583-599.

Little CHA, Lavigne MB, Ostaff DP. 2003. Impact of old foliage removal, simulating defoliation by the balsam fir sawfly, on balsam fir tree growth and photosynthesis of current-year shoots. Forest Ecology and Management 186, 261-269.

Meyer GA. 1998. Pattern of defoliation and its effect on photosynthesis and growth of goldenrod. Functional Ecology 12, 270-279.

Morgan JM. 1980. Osmotic adjustment in the spikelets and leaves of wheat. Journal of Experimental Botany 31, 655-665.

Morrison KD, Reekie EG. 1995. Pattern of defoliation and its effect on photosynthetic capacity in Oenothera biennis. Journal of Ecology 83, 759-767.

Nowak RS, Caldwell MM. 1984. A test of compensatory photosynthesis in the field implications for herbivory tolerance. Oecologia 61, 311-318.

Oleksyn J, Karolewski P, Giertych MJ, Zytkowiak R, Reich PB, Tjoelker MG. 1998. Primary and secondary host plants differ in leaf-level photosynthetic response to herbivory: evidence from Alnus and Betula grazed by the alder beetle, Agelastica alni. New Phytologist 140, 239-249.

Pinkard EA, Battaglia M, Mohammed CL. 2007. Defoliation and nitrogen effects on photosynthesis and growth of Eucalyptus globulus. Tree Physiology 27, 1053-1063.

Pinkard EA, Beadle CL, Davidson NJ, Battaglia M. 1998. Photosynthetic responses of Eucalyptus nitens (Deane and Maiden) maiden to green pruning. Trees-Structure and Function 12, 119-129.

Shimada S, Kokubun M, Shibata H, Matsui S. 1992. Effect of water supply and defoliation on photosynthesis, transpiration and yield of soybean. Japanese Journal of Crop Science 61, 264-270.

Teixeira EI, Moot DJ, Brown HE. 2008. Defoliation frequency and season affected radiation use efficiency and dry matter partitioning to roots of lucerne (Medicago sativa L.) crops. European Journal of Agronomy 28, 103-111.

Toft NL, McNaughton SJ, Georgiadis NJ. 1987. Effects of water stress and simulated grazing on leaf elongation and water relations of an east-African grass, Eustachys paspaloides. Australian Journal of Plant Physiology 14, 211-226.

Turnbull TL, Adams MA, Warren CR. 2007. Increased photosynthesis following partial defoliation of field-grown Eucalyptus globulus seedlings is not caused by increased leaf nitrogen. Tree Physiology 27, 1481-1492.

Virgona JM, Gummer FAJ, Angus JF. 2006. Effects of grazing on wheat growth, yield, development, water use, and nitrogen use. Australian Journal of Agricultural Research 57, 1307-1319. 
von Caemmerer S. 2000. Biochemical models of leaf photosynthesis. Collingwood, Melbourne: CSIRO Publishing.

von Caemmerer S, Evans JR, Hudson GS, Andrews TJ. 1994. The kinetics of ribulose1,5-bisphosphate carboxylase/oxygenase in-vivo inferred from measurements of photosynthesis in leaves of transgenic tobacco. Planta 195, 88-97.

von Caemmerer S, Farquhar GD. 1981. Some relationships between the biochemistry of photosynthesis and the gas exchange of leaves. Planta 153, 376-387.

von Caemmerer S, Farquhar GD. 1984. Effects of partial defoliation, changes of irradiance during growth, short-term water stress and growth at enhanced $\mathrm{p}\left(\mathrm{CO}_{2}\right)$ on the photosynthetic capacity of leaves of Phaseolus vulgaris L. Planta 160, 320-329.

Wareing PF, Khalifa MM, Treharne KJ. 1968. Rate limiting processes in photosynthesis at saturating light intensities. Nature 220, 453-457.

Winter SR, Thompson EK. 1987. Grazing duration effects on wheat growth and grain yield. Agronomy Journal 79, 110-114.

Yang Z, Midmore DJ. 2004. Experimental assessment of the impact of defoliation on growth and production of water-stressed maize and cotton plants. Experimental Agriculture 40, 189-199.

Zadoks JC, Chang TT, Konzak CF. 1974. Decimal code for growth stages of cereals. Weed Research 14, 415-421.

Zhao W, Chen SP, Han XG, Lin GH. 2009. Effects of long-term grazing on the morphological and functional traits of Leymus chinensis in the semiarid grassland of Inner Mongolia, China. Ecological Research 24, 99-108.

Zhou R, Quebedeaux B. 2003. Changes in photosynthesis and carbohydrate metabolism in mature apple leaves in response to whole plant source-sink manipulation. Journal of the American Society for Horticultural Science 128, 113-119. 